\title{
Detection of neuronal signatures by means of data-driven tomography
}

\author{
Carlos Aguirre*, Eduardo Serrano, Pedro Pascual \\ From Twenty Second Annual Computational Neuroscience Meeting: CNS*2013 \\ Paris, France. 13-18 July 2013
}

Time-frequency tomograms have been used for denoising and component separation of neuronal signals [1]. Time-frequency tomograms are particularly appropriate to identify the time unfolding of the frequency features of the signals. However there are components of neuronal signals, as the neural signatures, that are not well represented by a clear spectral pattern. In this case, a new kind of tomographic transform has been recently proposed, the data-driven tomography[2]. In particular, if in the linear combination of the tomographic operator $\mathrm{B}(\mu, v)=\mu t+v \mathrm{O}$, one chooses an operator $\mathrm{O}$, that is specially tuned to the features of the component that one wants to extract, then, by looking for the particular values of the set $(\mu=\cos (\theta), v=\sin (\theta))$ where the noise effects might cancel out, we may separate the information of very small signals from large noise and also obtain reliable information on the temporal structure of the signal.
We have generated a tuned operator from a typical set of neuronal signatures represented as a firing pattern inside a neuronal burst, we have then applied this data-driven operator to a neuronal signal obtained from a phenomenological model that allows spiking, bursting, subthreshold oscillations and neuronal signatures, we have also added a uniform noise to the neuronal signal. In Figure 1A the plot of the neural signal with noise is depicted, the neural signature is present inside both bursts.

In Figure 1B the plot color of the tomogram (higher values in red) is built for 20 different values of the parameter $\theta$ at intervals $\pi / 40$. We can see a set of high value coefficients concentrated in the 230 to 270 and 600 to 640 indexes suggesting the presence of the neural signature in both ranges of values. In Figure $1 \mathrm{C}$ the two neuronal signatures are extracted from the noisy original signal by projection for $\theta=8 \pi / 40$ from the higher value coefficients.

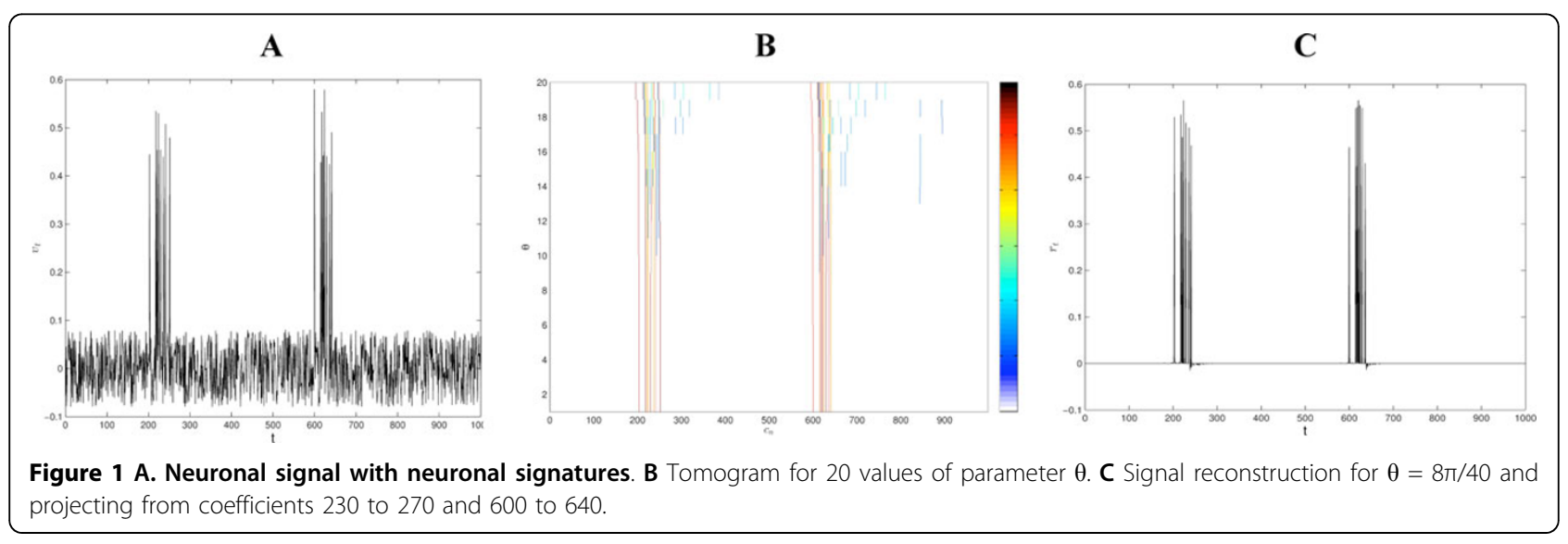

\footnotetext{
* Correspondence: Carlos.Aguirre@uam.es

GNB Department of Computer Science, Universidad Autónoma de Madrid, Madrid, 28049, Spain
}

C Biomed Central

C 2013 Aguirre et al; licensee BioMed Central Ltd. This is an Open Access article distributed under the terms of the Creative Commons Attribution License (http://creativecommons.org/licenses/by/2.0), which permits unrestricted use, distribution, and reproduction in any medium, provided the original work is properly cited. 


\section{Acknowledgements}

This work was supported by MINECO TIN2012-30883 and TIN-2010-19607.

Published: 8 July 2013

\section{References}

1. Aguirre C, Pascual P, Campos D, Serrano E: Single neuron transient activity detection by means of tomography. BMC Neuroscience 2011, 12(Suppl 1): P297.

2. Aguirre C, Vilela R: Signal recognition and adapted filtering by noncommutative tomography.[http://arxiv.org/pdf/1211.5986v1.pdf].

doi:10.1186/1471-2202-14-S1-P309

Cite this article as: Aguirre et al.: Detection of neuronal signatures by means of data-driven tomography. BMC Neuroscience 2013 14(Suppl 1): P309.

Submit your next manuscript to BioMed Central and take full advantage of:

- Convenient online submission

- Thorough peer review

- No space constraints or color figure charges

- Immediate publication on acceptance

- Inclusion in PubMed, CAS, Scopus and Google Scholar

- Research which is freely available for redistribution

Submit your manuscript at www.biomedcentral.com/submit
C Biomed Central 